\title{
Basic Strong Cation Exchange Chromatography, BaSCX, a Highly Efficient Approach for C-Terminomic Studies Using LysargiNase Digestion
}

Qingqing $\mathrm{Li}^{1,2}$, Yang Zhang ${ }^{1,2}$, Jingnan Huang ${ }^{1}$, Zhen $\mathrm{Wu}^{1}$, Langlang Tang ${ }^{1}$, Lin Huang ${ }^{1}$, Xumin Zhang ${ }^{*}$,1

1 State Key Laboratory of Genetic Engineering, Department of Biochemistry, School of Life Sciences, Fudan University, Shanghai 200438, China

2 Both authors contributed equally to this work

\section{Supplemental Information}

BaSCX Protocol S-2 - S-5

Figure S-1. The reproducibility of BaSCX method. S-6

Figure S-2. The overlap of identified human protein C-termini among COFRADIC, BaSCX and Du et al. method. S-7

Table S-1. List of identified protein C-termini in Human sample (HeLa cell and 293T cell).

Table S-2. List of identified protein C-termini in mouse Neuro-2a cell.

Table S-3. List of identified protein C-termini.in C.elegans.

Table S-4. List of identified protein C-termini in tomato.

Table S-5. List of 166 identified Neo-C-termini in Human sample (HeLa cell and 293T cell).

Table S-6. List of observed modified protein C-terminal peptides in Human sample (HeLa cell and 293T cell). 


\section{BaSCX Protocol}

\section{Sample preparation TIMING $3 \mathrm{~h}$}

1) Protein extraction. Firstly, collected cells are washed with PBS for three times. Then, cell lysate is applied by adding 20 volumes of lysis buffer ( $4 \mathrm{M}$ guanidine hydrochloride, $100 \mathrm{mM}$ TEAB, $10 \mathrm{mM}$ DTT) and sonicate for 20 $\min (2 \mathrm{~s}$ sonication with $5 \mathrm{~s}$ intervals). Lastly, centrifuge cell lysate $(20,000 \mathrm{~g}$, $20 \min , 4^{\circ} \mathrm{C}$ ) and collect the supernatant.

2) Protein determination. Protein concentration is determined using Bradford assay.

3) Reduction and alkylation. Add $10 \mathrm{mM} \mathrm{DTT}$ and incubate at $37^{\circ} \mathrm{C}$ for $45 \mathrm{~min}$. Next, add $100 \mathrm{mM}$ acrylamide and incubate at $25^{\circ} \mathrm{C}$ for $1 \mathrm{~h}$.

\section{Protection at protein level TIMING $12 \mathrm{~h}$}

4) Protein acetylation. Add $10 \mathrm{mM}$ Ac-NHS and incubate at $25^{\circ} \mathrm{C}$ for $1 \mathrm{~h}$. To achieve more complete protection, add another 10mM Ac-NHS and incubate at $25^{\circ} \mathrm{C}$ for $1 \mathrm{~h}$. After acetylation, $100 \mathrm{mM}$ Tris- $\mathrm{HCl}(\mathrm{pH} 8.80)$ is added to quench the Ac-NHS. And then $100 \mathrm{mM} \mathrm{NH}_{2} \mathrm{OH}$ is added to reverse the undesired partial acetylation on Ser/Thr/Tyr.

5) Buffer displacement. Transfer samples to Microcon PL-10 filter and centrifuge at $13,800 \mathrm{~g} 25{ }^{\circ} \mathrm{C}$ to cast away lysis buffer. With three-time displacement, samples are now dissolved in carboxyl protection buffer (4 M guanidine hydrochloride, $200 \mathrm{mM}$ MES and $2 \mathrm{M}$ ethanolamine, $\mathrm{pH} 4.5$ ).

6) Protein carboxyl protection. Add $50 \mathrm{mM}$ NHS and $100 \mathrm{mM}$ EDC to the filter and incubate at $25{ }^{\circ} \mathrm{C}$ for $2 \mathrm{~h}$. To achieve more complete protection, another $100 \mathrm{mM}$ EDC is added and incubate at $25^{\circ} \mathrm{C}$ for another $2 \mathrm{~h}$.

\section{Digestion TIMING 21-24 h}

7) Buffer displacement. Centrifuge at 13,800 g $25{ }^{\circ} \mathrm{C}$ to cast away carboxyl protection buffer. $400 \mu \mathrm{L}$ LysargiNase active buffer (50 mM HEPES and 10 
$\mathrm{mM} \mathrm{CaCl}_{2}, \mathrm{pH} 7.5$ ) with $20 \% \mathrm{ACN}$ and $400 \mu \mathrm{L}$ LysargiNase active buffer are added in order and centrifuge at same condition.

8) LysargiNase digestion. LysargiNase should be activated by incubating in LysargiNase active buffer for $12-16 \mathrm{~h}$ at $20{ }^{\circ} \mathrm{C}$ before use. Activated LysargiNase was added at the ratio of enzyme: protein as 1: 25 and the digestion was carried out at $37^{\circ} \mathrm{C}$ for $14 \mathrm{~h}$.

9) Sample collection. Centrifuge at $13,800 \mathrm{~g}$ at $25^{\circ} \mathrm{C}$ and collect the proteolytic peptides into new tubes. For better recovery of hydrophobic peptides, wash the filter with $20 \% \mathrm{ACN}$ and collect the filtrates by centrifuging at $13,800 \mathrm{~g}$.

10) Removing ACN. Remove ACN with Speedvac.

11) TEAB treatment. Add $500 \mathrm{mM}$ TEAB and incubate at $37^{\circ} \mathrm{C}$ for $12 \mathrm{~h}$.

\section{Desalting TIMING $6 \mathrm{~h}$}

12) Acidification. Add TFA to acidify the samples.

13) Sample desalting. Strata C18-E solid phase extraction (SPE) sorbents (55 $\mu \mathrm{m}$, $70 \AA$, 50mg/1mL, Phenomenex, USA) is used for desalting. Firstly, wash the column with ACN and equilibrate the column with $0.1 \%$ TFA. Next, load the acidic peptide and wash the column with $0.1 \%$ TFA. Lastly, $30 \%$ ACN and $60 \%$ ACN are used to elute peptides from columns successively, and the eluents are pooled together.

14) Sample drying. Dry the samples in Speedvac. The dried samples could be stored at $-20^{\circ} \mathrm{C}$.

\section{BaSCX TIMING $6 \mathrm{~h}$}

15) Peptide re-dissolving. Before SCX-HPLC, peptide samples are redissolved in buffer A (2 mM ammonium phosphate, $30 \% \mathrm{ACN}, \mathrm{pH} 8.0$ ).

16) BaSCX-HPLC. The mobile phase comprised buffer A (2 mM ammonium phosphate, $30 \% \mathrm{ACN}, \mathrm{pH} 8.0)$ and buffer B (2mM ammonium phosphate, 1 $\mathrm{M} \mathrm{NH}_{4} \mathrm{Cl}, 30 \% \mathrm{ACN}, \mathrm{pH} 8.0$ ). The gradient was: 0-10 min, 0\% buffer B, 200 
$\mu \mathrm{L} / \mathrm{min} ; 10-25 \mathrm{~min}, 0-50 \%$ buffer $\mathrm{B}, 200 \mu \mathrm{L} / \mathrm{min} ; 25-30 \mathrm{~min}, 50-100 \%$ buffer B, $200 \mu \mathrm{L} / \mathrm{min}$; 30-35 min, 100\% buffer B, $200 \mu \mathrm{L} / \mathrm{min}$; 35-36min, 100-0\% buffer B from, $300 \mu \mathrm{L} / \mathrm{min}$; $36-50 \mathrm{~min}, 0 \%$ buffer $\mathrm{B}, 300 \mu \mathrm{L} / \mathrm{min}$; $100 \mu \mathrm{g}$ peptides are loaded each time. Collect fractions from 12 to $23 \mathrm{~min}$.

17) Sample mixing. Take $80 \mu \mathrm{L}$ out from each fraction and mix together, then dry the samples by Speedvac to remove ACN.

\section{Desalting TIMING $2 \mathrm{~h}$}

18) Acidification. Add TFA to acidify the samples.

19) Sample desalting. Same method as above.

20) Reconstitute with $1 \%$ FA

\section{LC-ESI-MS/MS Analysis}

21)LC-ESI-MS/MS analysis was performed using an EASY-nLC 1000 system (Thermo Fisher Scientific, Odense, Denmark) coupled to an LTQ-Orbitrap Elite mass spectrometer (Thermo Fisher Scientific, Bremen, Germany). Samples were analyzed on a home-made C18 analytical column $(75 \mu \mathrm{m}$ i.d. $\times$ 25 cm, ReproSil-Pur 120 C18-AQ, $1.9 \mu \mathrm{m}$ (Dr. Maisch GmbH, Germany)). The mobile phases consisted of Solvent A (0.1\% formic acid) and Solvent B ( $0.1 \%$ formic acid in ACN). Samples were eluted in 120 min using the following gradients: $2-5 \% \mathrm{~B}$ in $2 \mathrm{~min}, 5-28 \% \mathrm{~B}$ in $98 \mathrm{~min}, 28-35 \% \mathrm{~B}$ in $5 \mathrm{~min}$. $35-90 \% \mathrm{~B}$ in $2 \mathrm{~min}$, and $90 \% \mathrm{~B}$ for $13 \mathrm{~min}$ at a flow rate of $200 \mathrm{~nL} / \mathrm{min}$. Data-dependent analysis was employed in MS analysis: After MS scan (resolution of 60000 at m/z 400; AGC target of $1 \mathrm{e} 6$ and maximum IIT of 100 $\mathrm{ms})$, the 15 most abundant ions were automatically selected and fragmented in HCD mode (AGC target of 5e4 and maximum IIT of $100 \mathrm{~ms}$; isolation width of $2 \mathrm{~m} / \mathrm{z}$; resolution of 15000 at m/z 400; normalized collision energy (NCE) of 35\%). Dynamic exclusion for $60 \mathrm{~s}$ was applied with a precursor mass tolerance of $10 \mathrm{ppm}$.

\section{Data Analysis}


22) The raw data were analyzed by Proteome Discoverer (version 1.4, Thermo Fisher Scientific) using an in-house Mascot server (version 2.3, Matrix Science, London, U.K.). Human protein database (20160213, 20,186 sequences) was downloaded from UniProt.

For identification search, data were searched using the following parameters: Arg-N as the enzyme; up to two missed cleavage sites were allowed; $10 \mathrm{ppm}$ mass tolerance for $\mathrm{MS}$ and $0.05 \mathrm{Da}$ for MS/MS fragment ions; propionamidation on cysteine, acetylation on lysine, ethanolamine protection on aspartate and glutamate as fixed modifications; acetylation on protein $\mathrm{N}$-terminus, ethanolamine protection on protein $\mathrm{C}$-terminus, oxidation on methionine as variable modifications.

For neo-C-termini search, data were searched using the following parameters: semiArg-N as the enzyme; up to two missed cleavage sites were allowed; 10 ppm mass tolerance for MS and $0.05 \mathrm{Da}$ for MS/MS fragment ions; propionamidation on cysteine, acetylation on lysine, ethanolamine protection on aspartate and glutamate as fixed modifications; acetylation on peptide $\mathrm{N}$-term, ethanolamine protection on peptide $\mathrm{C}$-term, oxidation on methionine as variable modifications. Before IceLogo analysis, Neo-termini possibly caused by trypsin and chymotrypsin were excluded.

The incorporated Percolator in Proteome Discoverer and the mascot expectation value was used to validate the search results and only the hits with FDR $\leq 0.01$ and MASCOT expected value $\leq 0.05$ were accepted for discussion. The mass spectrometry proteomics data have been deposited to the ProteomeXchange Consortium via the PRIDE partner repository with the dataset identifier PXD016317. ${ }^{23}$ 


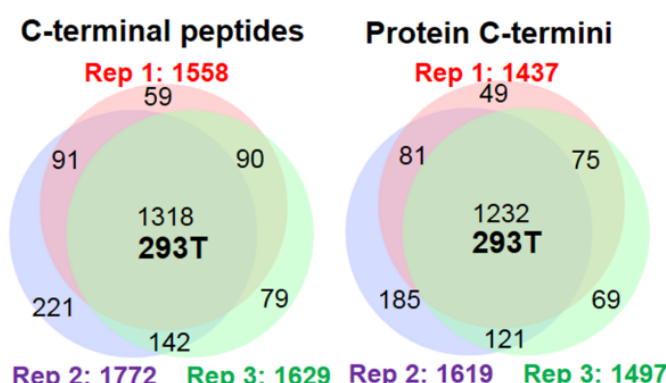

Rep 2: 1772 Rep 3: 1629 Rep 2: 1619 Rep 3: 1497

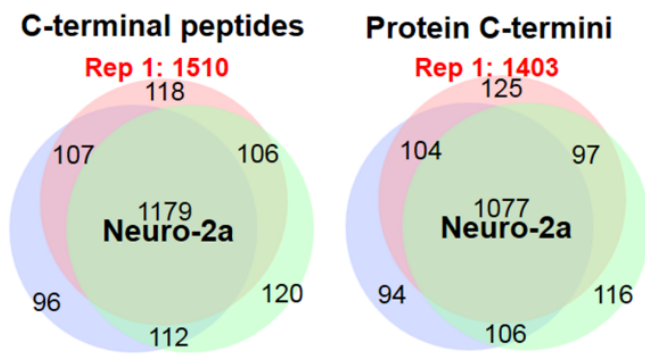

Rep 2: 1494 Rep 3: 1517 Rep 2: $1381 \quad$ Rep 3: 1396

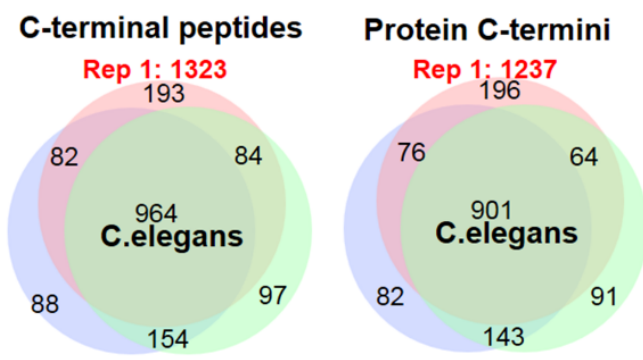

Rep 2: 1288 Rep 3: 1299 Rep 2: 1202 Rep 3: 1199

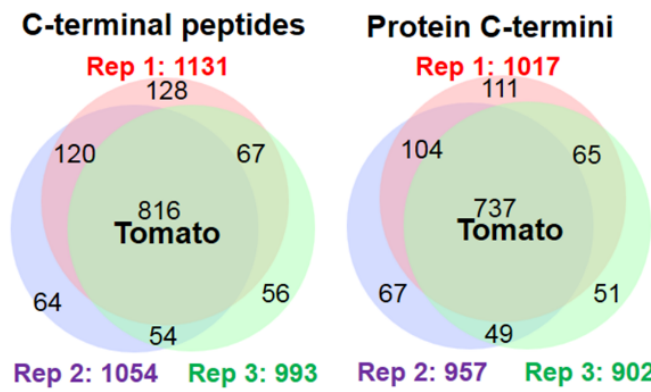

Figure S1. The reproducibility of BaSCX method at peptide level and protein level in 293T cell, mouse Neuro-2a cell, C.elegans and tomato sample. More than $76 \%$ of both protein C-terminal peptides and their corresponding proteins have been identified in at least duplicates. 


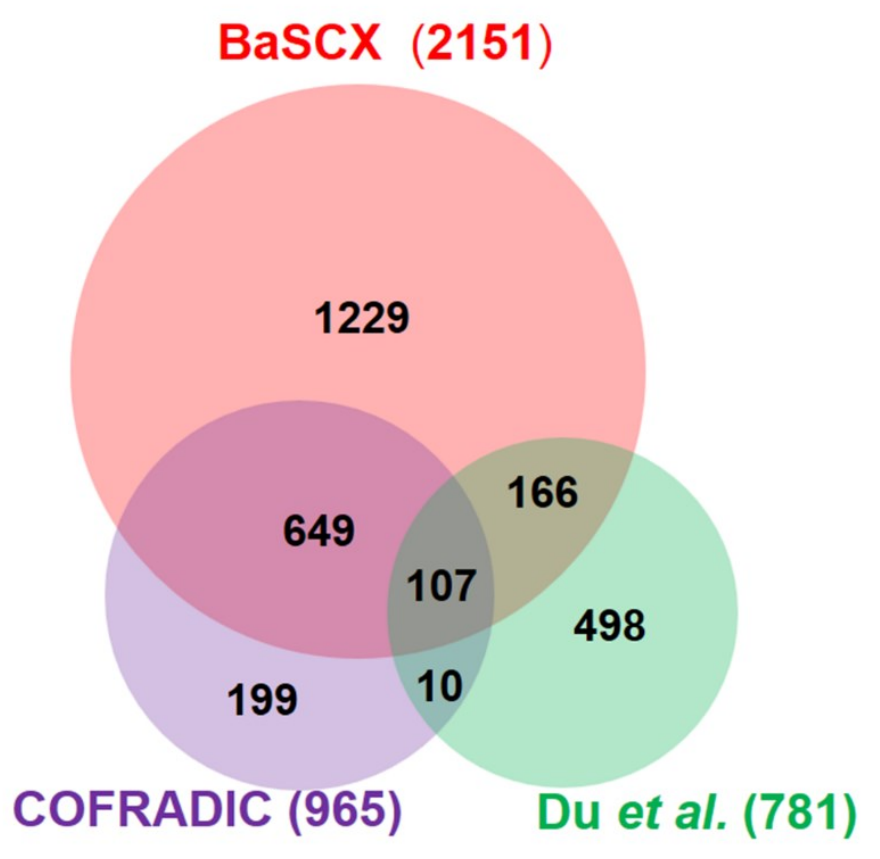

Figure S2. The overlap of the identified human protein C-termini among COFRADIC, BaSCX and Du's method. Among them, $107 \mathrm{C}$-termini were identified by all methods, whereas 199 (20.6\% in 965) C-termini were only identified in COFRADIC, 498 (63.8\% in 781) in Du's method and 1229 (57.1\% in 2151) in BaSCX method. 